\title{
Epidemiology of isolated preaxial polydactyly type I: Data from the Polish Registry of Congenital Malformations (PRCM)
}

\author{
Anna Materna-Kiryluk ${ }^{1 *}$, Aleksander Jamsheer ${ }^{1}$, Katarzyna Wisniewska², Barbara Wieckowska ${ }^{3}$, Janusz Limon ${ }^{4}$, \\ Maria Borszewska-Kornacka ${ }^{5}$, Henryka Sawulicka-Oleszczuk ${ }^{6}$, Ewa Szwalkiewicz-Warowicka ${ }^{7}$ \\ and Anna Latos-Bielenska ${ }^{1}$
}

\begin{abstract}
Background: Polydactyly represents a heterogeneous group of congenital hand and foot anomalies with variable clinical features and diverse etiology. Preaxial polydactyly type I (PPD1) is the most frequent form of preaxial polydactyly. The etiology of sporadic PPD1 remains largely unknown and the relative contribution of genetic and environmental factors is not clearly defined. The primary goals of this study are twofold: (1) to examine the epidemiology and clinical features of sporadic PPD1 in comparison to a healthy control group, and (2) to contrast the characteristics of sporadic PPD1 with familial forms of isolated polydactyly.

Methods: Among 2,530,349 live births registered in the Polish Registry of Congenital Malformations (PRCM), we identified 459 children with isolated sporadic PPD1 and 353 children with familial polydactyly, including 57 children with familial PPD1.

Results: In comparison with the matched group of 303 controls, sporadic PPD1 cases had significantly lower birth $\operatorname{order}(P=0.01)$ and birthweight $(P<0.0001)$. Similarly, when compared to familial cases of polydactyly, lower birth order $(P=0.047)$ and lower birthweight $(P<0.0001)$ were characteristic of sporadic PPD1 cases. Moreover, our analyses suggested several additional risk factors for sporadic PPD1, including lower paternal education levels $(P=0.01)$, upper respiratory tract infections during the first trimester of pregnancy $(P=0.049)$, and maternal history of epilepsy ( $P=0.01)$.
\end{abstract}

Conclusions: In summary, our study provides support to the hypothesis that non-genetic factors play an important role in the etiology of non-familiar PPD1.

Keywords: Polydactyly, Preaxial polydactyly type I, Registry

\section{Background}

Polydactyly represents a heterogeneous group of congenital anomalies involving hand and foot. The clinical features are highly variable and the etiology is largely unknown. Isolated polydactyly has been classified as preaxial, axial, or postaxial. While preaxial and postaxial polydactylies occur more frequently, axial forms are extremely rare. Preaxial polydactyly, defined as polydactyly on the radial side of the hands and tibial side of the feet,

\footnotetext{
*Correspondence: akiryluk@ump.edu.pl

${ }^{1}$ Chair and Department of Medical Genetics, Poznan University of Medical Sciences, Poznan, Poland Full list of author information is available at the end of the article
}

appears more heterogeneous than the postaxial form. There are four types of preaxial polydactyly: Type I (PPD1): thumb/hallux polydactyly, type II (PPD2): polydactyly of triphalangeal thumb, type III (PPD3): polydactyly of index finger, and type IV (PPD4): polysyndactyly. Among the four types, PPD1 is the most frequent form. Its characteristic feature is doubling of one or more skeletal components of a thumb or hallux. In its mildest form, it can manifest as a widening or small bifurcation of a thumb or hallux.

PPD1 exhibits differences in occurrence across various ethnic groups, but presently its genetics are not well understood. A small number of familial cases have been

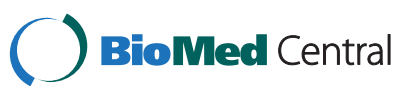


linked to the disruption of the Shh signal transduction pathway, which plays a major role in antero-posterior patterning of limbs [1]. Nevertheless, based on the previous epidemiologic investigations, environmental factors cannot be disregarded in the determination of this phenotype. For example, sporadic PPD1 has been observed more frequently in infants of diabetic mothers [2] and in babies with thalidomide embryopathy [3].

We undertake this work to better delineate the environmental factors associated with higher risk of sporadic PPD1. The goals of this work are twofold: (1) to examine the clinical features and the epidemiology of sporadic PPD1 in Poland, and (2) to compare epidemiologic characteristics of sporadic PPD1 with the familial forms of isolated polydactyly (more likely attributable to genetic causes).

\section{Methods}

\section{Cases}

Among 2,530,349 live births registered in the Polish Registry of Congenital Malformations (PRCM), we identified 459 children with isolated sporadic PPD1 and 353 children with familial polydactyly (including 57 children with familial PPD1). The data was collected between years 1998 and 2007 from 13 geographic regions of Poland, comprising approximately $85 \%$ of the total area of the country. The following regions were analyzed: dolnoslaskie, kujawsko-pomorskie, lubuskie, lodzkie, opolskie, pomorskie, warminsko-mazurskie, wielkopolskie, zachodniopomorskie (between 1998 and 2007), slaskie (between 2001 and 2007), lubelskie, podkarpackie (between 2002 and 2007) and mazowieckie (between 2004 and 2007). Standardized congenital malformation reporting questionnaires were used as a primary information source. The questionnaires were completed by physicians from neonatal and pediatric wards, and the information was entered into the Registry database. The organization of PRCM has been described in detail elsewhere [4]. The data analyzed in this study was collected as part of the PRCM registry, a member of the Eurocat network of population-based registries for the epidemiological surveillance of congenital anomalies. The authors include the founders and the coordinators of the PRCM registry. The authors have designed the data collection system, collected the primary data, managed the database, and performed all analyses presented in this study. These data will also be made available by the authors to any interested investigators upon a written request and approval of the local ethics committee.

The main criterion for the diagnosis was the presence of isolated sporadic defects: polydactyly type I (thumb/ hallux polydactyly). Exclusion criteria included: preaxial polydactyly type II, III, IV, familial preaxial polydactyly type I, postaxial polydactyly, and complex polydactyly (simultaneous pre- and postaxial). All known syndromes and chromosomal aberrations associated with multiple birth defects and polydactyly were also excluded.

\section{Controls}

Since healthy individuals without any malformation are not routinely reported to the registry, the control group was selected among individuals with a benign isolated mild ankyloglossia. Mild ankyloglossia (short lingular frenulum without clinical consequences), or "tongue tied", is the most common and benign oral anomaly caused by an unusually short thickened lingual frenulum, and thus it is highly unlikely to be etiologically related to polydactyly or limb malformations. To be eligible for inclusion in the control group, individuals with mild ankyloglosia, had no other congenital malformations, and were reported to the registry at the same time and from the same general area of residence as the polydactyly cases. Moreover, in order to assure that our controls were representative, they were matched to the general Polish newborn population with respect to sex distribution, maternal age, and maternal education level. The matching was performed using a random sampling procedure with a proportionate allocation within each stratum (a sampling fraction within each stratum was proportional to that of the general population). The stratified sampling was implemented in Excel (Microsoft, 2007). The data on the characteristics of the general population were obtained from the Central Polish Statistical Office [5]. In total, 303 of 612 initially available individuals with isolated mild ankyloglosia met our matching criteria and were included as controls in this study.

\section{Statistical analysis}

The univariate (unadjusted) comparisons of demographic and clinical risk factors across different study groups were conducted using the Fisher's exact test (categorical variables) or Student's t-test (continuous variables). Adjusted analyses were performed within the logistic regression framework, using StatXact and LogXact software version 8.0.0 (Cytel Studio). P-values $<0.05$ were considered statistically significant.

\section{Results}

Based on the PRCM reports, we estimated the incidence of sporadic PPD1 in Poland at 181.4 cases per million live birth-years. The sporadic cases of PPD1 were predominantly unilateral (92.8\%) and had a strong predilection for the hands (94.8\%). Among unilateral cases, sporadic thumb polydactyly occurred more frequently on the right side $(61.2 \%, \mathrm{P}<0.0001)$. We also noted a trend for sporadic hallux polydactyly to occur more commonly on the left side $(71.4 \%, \mathrm{P}=0.08)$. These observations are summarized in Table 1. 
Table 1 Laterality of limb defects in sporadic preaxial polydactyly type I (PPD1), Polish Registry of Congenital Malformations, 1998-2007

\begin{tabular}{|c|c|c|c|c|}
\hline \multirow[t]{3}{*}{ Characteristic } & \multicolumn{4}{|c|}{ Sporadic PPD1 N=459 } \\
\hline & \multicolumn{2}{|c|}{ Thumb } & \multicolumn{2}{|c|}{ Hallux } \\
\hline & $N=435$ & P-value & $\mathrm{N}=24$ & P-value \\
\hline Unilateral & 405 & & 21 & \\
\hline Left & $157(38.8 \%)$ & $<0.0001$ & $15(71.4 \%)$ & 0.08 (NS) \\
\hline Right & $248(61.2 \%)$ & & $6(28.6 \%)$ & \\
\hline Bilateral & 18 & & 3 & \\
\hline Unknown & 12 & & 0 & \\
\hline
\end{tabular}

Statistical significance of exact test for proportion R:L ratio $=1$. NS: Not significant.

The incidence of familial polydactyly in Poland was estimated at 139.5 cases per million live birth-years. In total, approximately $50 \%$ of index cases with positive family history had at least one affected parent, $26 \%$ had at least one affected sibling, and $17 \%$ had at least one affected grandparent. The exact numbers of affected first- and second-degree relatives by type of polydactyly is summarized in Table 2.

The characteristics of cases with sporadic PPD1, familial cases of polydactyly, and the controls are summarized and compared in Table 3. Interestingly, both types of polydactyly were more common in males (maleto-female ratio of 1.29). Low birthweight was the most significant risk factor associated with sporadic PPD1. The risk for sporadic PPD1 decreased by approximately $31 \%$ with each extra $500 \mathrm{~g}$ gain in body weight $(\mathrm{OR}=0.69$, [95\% CI: $0.61-0.79$ per $500 \mathrm{~g}$ body weight], $\mathrm{P}<0.0001)$. Other associated risk factors for sporadic PPD1 included earlier pregnancy and lower birth order $\quad(\mathrm{OR}=0.87$ per each subsequent pregnancy, [95\% CI: 0.77-0.97], $\mathrm{P}=0.02$ and $\mathrm{OR}=0.84$ per each subsequent birth, [95\% CI: 0.74-0.96], P = 0.01). We also observed a trend for a higher risk of sporadic PPD1 with lower paternal education $(\mathrm{OR}=0.81$ per each education level, [95\% CI: 0.64-1.01], P=0.06). None of the above trends or associations was observed for the familial forms of polydactyly.

Next, we directly compared the sporadic and familial forms of polydactyly (Table 4). Here, we again noted higher risk of sporadic PPD1 with low birthweight (OR $=0.74$, [95\% CI: $0.65-0.84$ per 500 g body weight], $\mathrm{P}<0.0001)$, lower birth order $(\mathrm{OR}=0.89$, [95\% CI: 0.780.998], $\mathrm{P}=0.047$ ), and lower paternal education levels $(\mathrm{OR}=0.76$, [95\% CI: 0.62-0.93], $\mathrm{P}=0.01)$. The sex distribution, urban/rural residence, maternal education and number of spontaneous abortions were not different between the two case groups.

Lastly, we performed the analysis of pregnancy complications and chronic maternal conditions (Table 5). Overall, the reported complications were rare across the three groups, thus our analysis may be underpowered. However, several interesting patterns arouse from this analysis. First, the pregnancy complications of oligohydramnios and polyhydramnios were absent in the healthy control group. However, oligohydramnios was more common in both polydactyly groups, with frequencies comparable between the sporadic and familial forms ( $1.5 \%$ and $1.7 \%$, respectively). In contrast, polyhydramnios appeared exclusively in the familial cases (1.1\%). Additionally, our analyses suggested that upper respiratory tract infections during the first trimester of pregnancy were associated with an increased risk of sporadic PPD1 $(4.1 \%$ vs. $1.7 \%, \quad \mathrm{P}=0.049)$, but not the familial forms of polydactyly $(P=0.11)$. We also noted a more frequent occurrence of epilepsy in mothers of children with PPD1 (1.7\%) when compared to the familial forms (0\%) or healthy controls $(0.3 \%)$. Importantly, maternal smoking history during the first trimester of pregnancy was not appreciably associated with the risk of either form of polydactyly.

Table 2 The number of affected first- and second-degree relatives of index cases with familial polydactyly reported to the Polish Registry of Congenital Malformations, 1998-2007

\begin{tabular}{|c|c|c|c|c|}
\hline \multirow{2}{*}{$\begin{array}{l}\text { Type of Familial } \\
\text { Polydactyly }\end{array}$} & \multicolumn{2}{|c|}{ Relatives $I^{\circ}$} & \multicolumn{2}{|c|}{ Relatives II $^{\circ}$} \\
\hline & Siblings & Parents & Grandparents & Parents' siblings \\
\hline Preaxial - PPD $(N=78)$ & $15(19.2 \%)$ & $31(39.7 \%)$ & $16(20.5 \%)$ & $17(21.8 \%)$ \\
\hline PPD1 (N = 57) & 14 & 17 & 10 & 12 \\
\hline $\operatorname{PPD} 2(\mathrm{~N}=1)$ & 0 & 1 & 1 & 0 \\
\hline PPD3 $(N=5)$ & 0 & 4 & 0 & 0 \\
\hline PPD4 $(N=14)$ & 1 & 9 & 4 & 5 \\
\hline PPD1 + PPD2 $(\mathrm{N}=1)$ & 1 & 0 & 1 & 0 \\
\hline Postaxial $(N=148)$ & $38(25.7 \%)$ & $77(52.0 \%)$ & $24(16.2 \%)$ & $40(27.0 \%)$ \\
\hline Unknown $(\mathrm{N}=127)$ & 39 (30.7\%) & 70 (55.1\%) & $21(16.5 \%)$ & 29 (22.8\%) \\
\hline Total $(\mathrm{N}=353)$ & 92 (26.1\%) & 178 (50.4\%) & 61 (17.3\%) & 86 (24.3\%) \\
\hline
\end{tabular}


Table 3 Demographic and clinical characteristics of sporadic preaxial polydactyly type I (PPD1), familial polydactyly (all types), and healthy control group

\begin{tabular}{|c|c|c|c|c|c|}
\hline \multirow[t]{3}{*}{ Characteristic } & \multirow{3}{*}{$\begin{array}{l}\text { Controls } \\
\mathrm{N}=303^{\$} \\
\text { Count (\%) }\end{array}$} & \multirow{2}{*}{\multicolumn{2}{|c|}{$\begin{array}{c}\text { Sporadic PPD1 } \\
\mathrm{N}=459^{\$}\end{array}$}} & \multirow{2}{*}{\multicolumn{2}{|c|}{$\begin{array}{l}\text { Familial Polydactyly } \\
\qquad \mathrm{N}=353^{5}\end{array}$}} \\
\hline & & & & & \\
\hline & & Count (\%) & P-value OR $[95 \% \mathrm{Cl}]$ & Count (\%) & P-value OR $[95 \% \mathrm{Cl}]$ \\
\hline \multicolumn{6}{|l|}{ Gender } \\
\hline Female (reference) & $135(44.6 \%)$ & $200(43.6 \%)$ & 0.83 (NS) & $154(43.6 \%)$ & 0.84 (NS) \\
\hline Male & $168(55.4 \%)$ & $257(56 \%)$ & $1.03[0.77,1.38]$ & $198(56.1 \%)$ & $1.03[0.76,1.41]$ \\
\hline \multicolumn{6}{|l|}{ Residence type } \\
\hline Urban (reference) & $179(60.3 \%)$ & $282(61.8 \%)$ & 0.67 (NS) & $210(60 \%)$ & 0.94 (NS) \\
\hline Rural & 118 (39.7\%) & $174(38.2 \%)$ & $0.94[0.69,1.26]$ & $140(40 \%)$ & $1.01[0.74,1.39]$ \\
\hline \multicolumn{6}{|l|}{ Maternal age $e^{\#}$} \\
\hline 19 years and less & $20(6.6 \%)$ & $36(7.8 \%)$ & & $28(7.9 \%)$ & \\
\hline $20-24$ & $81(26.7 \%)$ & 147 (32\%) & & $94(26.6 \%)$ & \\
\hline $25-29$ & $110(36.3 \%)$ & 147 (32\%) & 0.57 (NS) & $128(36.3 \%)$ & 0.95 (NS) \\
\hline $30-34$ & $63(20.8 \%)$ & $91(19.8 \%)$ & $0.99[0.95,1.03]$ & $61(17.3 \%)$ & $1.00[0.96,1.04]$ \\
\hline $35-39$ & $25(8.3 \%)$ & $28(6.1 \%)$ & & $28(7.9 \%)$ & \\
\hline 40 years and more & $4(1.3 \%)$ & $5(1.1 \%)$ & & $13(3.7 \%)$ & \\
\hline \multicolumn{6}{|l|}{ Paternal age } \\
\hline 19 years and less & $7(2.3 \%)$ & $11(2.4 \%)$ & & $6(1.7 \%)$ & \\
\hline $20-24$ & $36(11.9 \%)$ & $81(17.6 \%)$ & & $52(14.7 \%)$ & \\
\hline $25-29$ & $98(32.3 \%)$ & $154(33.6 \%)$ & & $115(32.6 \%)$ & \\
\hline $30-34$ & $74(24.4 \%)$ & 115 (25.1\%) & 0.27 (NS) & $84(23.8 \%)$ & 0.95 (NS) \\
\hline $35-39$ & $39(12.9 \%)$ & $54(11.8 \%)$ & $0.98[0.95,1.02]$ & $49(13.9 \%)$ & $1.00[0.97,1.04]$ \\
\hline $40-44$ & $20(6.6 \%)$ & $24(5.2 \%)$ & & $26(7.4 \%)$ & \\
\hline $45-49$ & $5(1.7 \%)$ & $5(1.1 \%)$ & & $9(2.5 \%)$ & \\
\hline 50 years and more & $2(0.7 \%)$ & $0(0 \%)$ & & $3(0.8 \%)$ & \\
\hline \multicolumn{6}{|l|}{ Maternal education $^{*}$} \\
\hline Elementary or incomplete elementary & $43(14.2 \%)$ & $63(13.7 \%)$ & & $41(11.6 \%)$ & \\
\hline Vocational & $91(30 \%)$ & 115 (25.1\%) & 0.14 (NS) & $105(29.7 \%)$ & 0.67 (NS) \\
\hline Secondary & $108(35.6 \%)$ & $160(34.9 \%)$ & $1.16[0.95,1.42]$ & $106(30 \%)$ & $1.05[0.85,1.30]$ \\
\hline Higher & $61(20.1 \%)$ & $94(20.5 \%)$ & & $87(24.6 \%)$ & \\
\hline \multicolumn{6}{|l|}{ Paternal education ${ }^{*}$} \\
\hline Elementary or incomplete elementary & $21(6.9 \%)$ & $51(11.1 \%)$ & & $32(9.1 \%)$ & \\
\hline Vocational & $128(42.2 \%)$ & $196(42.7 \%)$ & 0.06 (NS) & $135(38.2 \%)$ & 0.50 (NS) \\
\hline Secondary & $83(27.4 \%)$ & 119 (25.9\%) & $0.81[0.64,1.01]$ & $96(27.2 \%)$ & $1.09[0.86,1.38]$ \\
\hline Higher & $36(11.9 \%)$ & $55(12 \%)$ & & $65(18.4 \%)$ & \\
\hline \multicolumn{6}{|l|}{ Birthweight [per $500 \mathrm{~g}$ body weight] } \\
\hline $500-999 \mathrm{~g}$ & $1(0 \%)$ & $2(0.4 \%)$ & & $1(0.3 \%)$ & \\
\hline 1000-1499 & $1(0.3 \%)$ & $6(1.3 \%)$ & & $1(0.3 \%)$ & \\
\hline 1500-1999 & $9(0.3 \%)$ & $9(2 \%)$ & & $4(1.1 \%)$ & \\
\hline $2000-2499$ & $46(3 \%)$ & $25(5.4 \%)$ & $<0.0001$ & $10(2.8 \%)$ & 0.32 (NS) \\
\hline $2500-2999$ & $101(15.2 \%)$ & $100(21.8 \%)$ & $0.69[0.61,0.79]$ & $46(13 \%)$ & $0.93[0.81,1.07]$ \\
\hline 3000-3499 & 102 (33.3\%) & 175 (38.1\%) & & 140 (39.7\%) & \\
\hline 3500-3999 & $34(33.7 \%)$ & 101 (22\%) & & 102 (28.9\%) & \\
\hline 4000-4499 & 7 (11.2\%) & 29 (6.3\%) & & $41(11.6 \%)$ & \\
\hline $4500 \mathrm{~g}$ or more & $0(2.3 \%)$ & $4(0.9 \%)$ & & $4(1.1 \%)$ & \\
\hline
\end{tabular}


Table 3 Demographic and clinical characteristics of sporadic preaxial polydactyly type I (PPD1), familial polydactyly (all types), and healthy control group (Continued)

\begin{tabular}{|c|c|c|c|c|c|}
\hline \multicolumn{6}{|l|}{ Pregnancy length } \\
\hline under 28 weeks & $0(0 \%)$ & $1(0.2 \%)$ & & $1(0.3 \%)$ & \\
\hline $28-31$ & $1(0.3 \%)$ & 7 (1.5\%) & 0.57 (NS) & $3(0.8 \%)$ & 0.48 (NS) \\
\hline $32-36$ & $15(5 \%)$ & $26(5.7 \%)$ & $0.98[0.90,1.06]$ & $15(4.2 \%)$ & $1.03[0.95,1.13]$ \\
\hline $37-41$ & $271(89.4 \%)$ & $397(86.5 \%)$ & & 305 (86.4\%) & \\
\hline 42 weeks or more & $8(2.6 \%)$ & $20(4.4 \%)$ & & $18(5.1 \%)$ & \\
\hline \multicolumn{6}{|l|}{ Pregnancy order } \\
\hline 1 & $126(41.6 \%)$ & $217(47.3 \%)$ & & $155(43.9 \%)$ & \\
\hline 2 & 87 (28.7\%) & 147 (32\%) & & 115 (32.6\%) & \\
\hline 3 & $45(14.9 \%)$ & $48(10.5 \%)$ & 0.02 & 39 (11\%) & 0.42 (NS) \\
\hline 4 & $28(9.2 \%)$ & $29(6.3 \%)$ & $0.87[0.77,0.97]$ & $15(4.2 \%)$ & $0.95[0.85,1.07]$ \\
\hline 5 & $13(4.3 \%)$ & $5(1.1 \%)$ & & $12(3.4 \%)$ & \\
\hline 6 & $2(0.7 \%)$ & $6(1.3 \%)$ & & $5(1.4 \%)$ & \\
\hline 7 or more & $2(0.7 \%)$ & $4(0.9 \%)$ & & $7(2 \%)$ & \\
\hline \multicolumn{6}{|l|}{ Birth order } \\
\hline 1 & $135(44.6 \%)$ & $237(51.6 \%)$ & & $166(47 \%)$ & \\
\hline 2 & 97 (32\%) & $152(33.1 \%)$ & & $117(33.1 \%)$ & \\
\hline 3 & $36(11.9 \%)$ & $37(8.1 \%)$ & 0.01 & 35 (9.9\%) & 0.62 (NS) \\
\hline 4 & $29(9.6 \%)$ & $19(4.1 \%)$ & $0.84[0.74,0.96]$ & $12(3.4 \%)$ & $0.97[0.86,1.10]$ \\
\hline 5 & $3(1 \%)$ & $5(1.1 \%)$ & & $8(2.3 \%)$ & \\
\hline 6 & $1(0.3 \%)$ & $4(0.9 \%)$ & & $6(1.7 \%)$ & \\
\hline 7 or more & $2(0.7 \%)$ & $2(0.4 \%)$ & & $4(1.1 \%)$ & \\
\hline \multicolumn{6}{|c|}{ Number of spontaneous abortions for 2nd or further pregnancy } \\
\hline No (reference) & $135(76.3 \%)$ & $182(75.2 \%)$ & 0.98 (NS) & $155(78.3 \%)$ & 0.35 (NS) \\
\hline Yes & $42(23.7 \%)$ & $57(23.6 \%)$ & $0.99[0.63,1.57]$ & $38(19.2 \%)$ & $0.79[0.48,1.30]$ \\
\hline
\end{tabular}

\section{Discussion}

Recent advances in human genetics led to successful discovery of molecular etiology underlying several types of familial polydactyly [1,6-9]. However, the etiology of sporadic PPD1 remains largely unexplained and the relative contribution of genetic and environmental factors is not clear. Our results suggest that environmental factors may play an important role in the determination of this phenotype.

The PRCM collects data on congenital malformations diagnosed among Polish children less than 2 years of age. The large numbers of polydactyly cases reported to PRCM enabled us to perform a well-powered comparison between familial and sporadic forms of this defect. In addition, we included a well-characterized group of healthy control births to further validate risk factors specific to sporadic PPD1. Nevertheless, several limitations of our study need to be mentioned. Although the PRCM currently monitors both live births and stillbirths, and multiple-source surveillance systems ensure the completeness of data on congenital malformations in live births, the data on the congenital malformations in stillbirths is incomplete. Because of this limitation, only live birth cases of isolated congenital malformations were used in our analysis. Other limitations stem from the intrinsic properties of registry data that may be susceptible to under-reporting or misdiagnosis. For example, there is a possibility that some forms of polydactyly, such as PPD4 with incomplete expression in lower extremities or without syndactyly, could have been misclassified as PPD1. Another limitation pertains to the nature of our control group. Although carefully matched to the general Polish population based on the demographic characteristics, the controls carried a diagnosis of a benign defect of lingual frenulum. There is no known association of this defect with polydactyly, or with any of the maternal or fetal characteristics under investigation in our study, thus it is highly unlikely that 
Table 4 Demographic and clinical characteristics of sporadic preaxial polydactyly type I (PPD1) and familial polydactyly (all types)

\begin{tabular}{|c|c|c|c|}
\hline Characteristic & $\begin{array}{l}\text { Sporadic PPD1 } \\
\qquad \mathrm{N}=459^{\$}\end{array}$ & $\begin{array}{l}\text { Familial Polydactyly } \\
\qquad \mathrm{N}=353^{\$}\end{array}$ & $\begin{array}{c}\text { P-value } \\
\text { OR [95\% CI] }\end{array}$ \\
\hline & Count (\%) & Count (\%) & \\
\hline \multicolumn{4}{|l|}{ Gender } \\
\hline Female (reference) & $200(43.6 \%)$ & $154(43.6 \%)$ & 0.99 (NS) \\
\hline Male & $257(56 \%)$ & $198(56.1 \%)$ & $1.00[0.75,1.32]$ \\
\hline \multicolumn{4}{|l|}{ Residence type } \\
\hline Urban (reference) & $282(61.8 \%)$ & $210(60 \%)$ & 0.60 (NS) \\
\hline Rural & $174(38.2 \%)$ & $140(40 \%)$ & $0.93[0.70,1.23]$ \\
\hline \multicolumn{4}{|l|}{ Maternal age } \\
\hline 19 years and less & $36(7.8 \%)$ & $28(7.9 \%)$ & \\
\hline $20-24$ & 147 (32\%) & $94(26.6 \%)$ & \\
\hline $25-29$ & 147 (32\%) & $128(36.3 \%)$ & 0.55 (NS) \\
\hline $30-34$ & 91 (19.8\%) & $61(17.3 \%)$ & $0.99[0.95,1.03]$ \\
\hline $35-39$ & $28(6.1 \%)$ & $28(7.9 \%)$ & \\
\hline 40 years and more & $5(1.1 \%)$ & $13(3.7 \%)$ & \\
\hline \multicolumn{4}{|l|}{ Paternal age ${ }^{\#}$} \\
\hline 19 years and less & $11(2.4 \%)$ & $6(1.7 \%)$ & \\
\hline $20-24$ & $81(17.6 \%)$ & $52(14.7 \%)$ & \\
\hline $25-29$ & $154(33.6 \%)$ & $115(32.6 \%)$ & \\
\hline $30-34$ & $115(25.1 \%)$ & 84 (23.8\%) & 0.23 (NS) \\
\hline $35-39$ & $54(11.8 \%)$ & 49 (13.9\%) & $0.98[0.95,1.01]$ \\
\hline $40-44$ & $24(5.2 \%)$ & $26(7.4 \%)$ & \\
\hline $45-49$ & $5(1.1 \%)$ & $9(2.5 \%)$ & \\
\hline 50 years and more & $0(0 \%)$ & $3(0.8 \%)$ & \\
\hline \multicolumn{4}{|l|}{ Maternal education $^{*}$} \\
\hline Elementary and incomplete elementary & $63(13.7 \%)$ & $41(11.6 \%)$ & \\
\hline Vocational & $115(25.1 \%)$ & $105(29.7 \%)$ & 0.32 (NS) \\
\hline Secondary & $160(34.9 \%)$ & $106(30 \%)$ & $1.10[0.91,1.33]$ \\
\hline Higher & $94(20.5 \%)$ & $87(24.6 \%)$ & \\
\hline \multicolumn{4}{|l|}{ Paternal education ${ }^{*}$} \\
\hline Elementary and incomplete elementary & $51(11.1 \%)$ & $32(9.1 \%)$ & 0.01 \\
\hline Vocational & $196(42.7 \%)$ & $135(38.2 \%)$ & $0.76[0.62,0.93]$ \\
\hline Secondary & $119(25.9 \%)$ & $96(27.2 \%)$ & \\
\hline Higher & $55(12 \%)$ & 65 (18.4\%) & \\
\hline \multicolumn{4}{|l|}{ Birthweight [per $500 \mathrm{~g}$ body weight] } \\
\hline $500-999 \mathrm{~g}$ & $2(0.4 \%)$ & $1(0.3 \%)$ & \\
\hline $1000-1499$ & $6(1.3 \%)$ & $1(0.3 \%)$ & \\
\hline 1500-1999 & $9(2 \%)$ & $4(1.1 \%)$ & \\
\hline 2000-2499 & $25(5.4 \%)$ & $10(2.8 \%)$ & $<0.0001$ \\
\hline 2500-2999 & $100(21.8 \%)$ & $46(13 \%)$ & $0.74[0.65,0.84]$ \\
\hline 3000-3499 & $175(38.1 \%)$ & $140(39.7 \%)$ & \\
\hline 3500-3999 & $101(22 \%)$ & $102(28.9 \%)$ & \\
\hline
\end{tabular}


Table 4 Demographic and clinical characteristics of sporadic preaxial polydactyly type I (PPD1) and familial polydactyly (all types) (Continued)

\begin{tabular}{|c|c|c|c|}
\hline $4000-4499$ & $29(6.3 \%)$ & $41(11.6 \%)$ & \\
\hline $4500 \mathrm{~g}$ and more & $4(0.9 \%)$ & $4(1.1 \%)$ & \\
\hline \multicolumn{4}{|l|}{ Pregnancy length } \\
\hline under 28 weeks & $1(0.2 \%)$ & $1(0.3 \%)$ & \\
\hline $28-31$ & $7(1.5 \%)$ & $3(0.8 \%)$ & 0.21 (NS) \\
\hline $32-36$ & $26(5.7 \%)$ & $15(4.2 \%)$ & $0.95[0.89,1.03]$ \\
\hline $37-41$ & $397(86.5 \%)$ & $305(86.4 \%)$ & \\
\hline 42 weeks and more & $20(4.4 \%)$ & $18(5.1 \%)$ & \\
\hline \multicolumn{4}{|l|}{ Pregnancy order } \\
\hline 1 & $217(47.3 \%)$ & 155 (43.9\%) & \\
\hline 2 & 147 (32\%) & $115(32.6 \%)$ & \\
\hline 3 & $48(10.5 \%)$ & $39(11 \%)$ & 0.13 (NS) \\
\hline 4 & $29(6.3 \%)$ & 15 (4.2\%) & $0.92[0.83,1.03]$ \\
\hline 5 & $5(1.1 \%)$ & $12(3.4 \%)$ & \\
\hline 6 & $6(1.3 \%)$ & $5(1.4 \%)$ & \\
\hline 7 and further & $4(0.9 \%)$ & $7(2 \%)$ & \\
\hline \multicolumn{4}{|l|}{ Birth order } \\
\hline 1 & 237 (51.6\%) & 166 (47\%) & \\
\hline 2 & $152(33.1 \%)$ & $117(33.1 \%)$ & \\
\hline 3 & 37 (8.1\%) & 35 (9.9\%) & 0.047 \\
\hline 4 & 19 (4.1\%) & $12(3.4 \%)$ & $0.89[0.78,0.998$ \\
\hline 5 & $5(1.1 \%)$ & $8(2.3 \%)$ & \\
\hline 6 & $4(0.9 \%)$ & $6(1.7 \%)$ & \\
\hline 7 and further & $2(0.4 \%)$ & $4(1.1 \%)$ & \\
\hline \multicolumn{4}{|c|}{ Number of spontaneous abortions for 2nd or further pregnancy } \\
\hline No (reference) & $182(75.2 \%)$ & $155(78.3 \%)$ & 0.30 (NS) \\
\hline Yes & $57(23.6 \%)$ & $38(19.2 \%)$ & $1.28[0.80,2.04]$ \\
\hline
\end{tabular}

${ }^{\$}$ Marginal totals for some variables may be different because of missing values. NS: Not significant.

" Common model of logistic regression of parents' age.

* Common model of logistic regression of parent's education.

this limitation confounded our results. Finally, our study is based on reports from a single country with predominantly white/Caucasian population, thus our data may not be generalizable to other nationalities or ethnicities.

Despite these limitations, our data demonstrate that lower birthweight is a very strong and highly significant risk factor only for sporadic PPD1, but not for the familial forms of polydactyly. Low birthweight is correlated with many environmental and socio-economic factors, such as unemployment, lower occupational status, or single mother status $[10,11]$. Therefore, our findings strongly argue for a role of environmental influence on the etiology of PPD1. Notably, the association of low birthweight with increased risk of isolated PPD1 has been reported previously [12].

Our data also suggests that lower level of the paternal education increases the risk of PPD1. The level of education represents another marker of socio-economic status, and is inversely correlated with certain health behaviors, such as smoking or drug use [13,14]. This factor has not been previously examined in relationship to the risk of polydactyly, thus additional studies are needed to validate our observations.

The effect of pregnancy complications and chronic medical conditions in mothers of children with polydactyly has been studied previously. One of the largest studies of 5,171 children with a variety of digital anomalies including polydactyly, syndactyly and adactyly demonstrated that the mothers of these children were more likely to suffer from anemia, cardiac disease, lung disease, oligohydramnios, polyhydramnios, or pregnancy-associated hypertension [15]. Other implicated maternal risk factors include vaginal bleeding in the first trimester [12], and diabetes $[2,15,16]$. In this 
Table 5 Differences in pregnancy complications between the controls, sporadic PPD1, and familial polydactyly (all types)

\begin{tabular}{|c|c|c|c|c|c|c|}
\hline \multirow[t]{3}{*}{ Characteristics } & Controls & $\begin{array}{l}\text { Sporadic } \\
\text { PPD1 }\end{array}$ & $\begin{array}{c}\text { Familial } \\
\text { Polydactyly }\end{array}$ & $\begin{array}{l}\text { Sporadic vs. } \\
\text { Controls }\end{array}$ & $\begin{array}{l}\text { Familial vs. } \\
\text { Controls }\end{array}$ & $\begin{array}{l}\text { Sporadic vs. } \\
\text { Familial }\end{array}$ \\
\hline & $\mathrm{N}=303^{5}$ & $\mathrm{~N}=459^{\mathrm{s}}$ & $\mathrm{N}=353^{\$}$ & & & \\
\hline & $\begin{array}{c}\text { Count } \\
(\%)\end{array}$ & Count (\%) & Count (\%) & $\begin{array}{c}\text { P-value } \\
\text { (Fisher's Exact } \\
\text { Test) }\end{array}$ & $\begin{array}{c}\text { P-value } \\
\text { (Fisher's Exact } \\
\text { Test) }\end{array}$ & $\begin{array}{c}\text { P-value } \\
\text { (Fisher's Exact } \\
\text { Test) }\end{array}$ \\
\hline \multicolumn{7}{|l|}{ Pregnancy pathology } \\
\hline Oligohydramnios & $0(0 \%)$ & $7(1.5 \%)$ & $6(1.7 \%)$ & 0.03 & 0.02 & 0.84 (NS) \\
\hline Polyhydramnios & $0(0 \%)$ & $0(0 \%)$ & $4(1.1 \%)$ & 1.00 (NS) & 0.09 (NS) & 0.035 \\
\hline Gestosis & $13(4.3 \%)$ & $15(3.3 \%)$ & $9(2.5 \%)$ & 0.45 (NS) & 0.22 (NS) & 0.56 (NS) \\
\hline $\begin{array}{l}\text { Upper respiratory tract infections during 1st } \\
\text { trimester of pregnancy }\end{array}$ & $5(1.7 \%)$ & $19(4.1 \%)$ & $13(3.7 \%)$ & 0.049 & 0.11 (NS) & 0.76 (NS) \\
\hline $\begin{array}{l}\text { Urinary system infections during 1st trimester of } \\
\text { pregnancy }\end{array}$ & $3(1 \%)$ & $5(1.1 \%)$ & $3(0.8 \%)$ & 0.90 (NS) & 0.88 (NS) & 0.77 (NS) \\
\hline \multicolumn{7}{|l|}{ Mother's chronic diseases } \\
\hline Hypothyroidism & $0(0 \%)$ & $4(0.9 \%)$ & $2(0.6 \%)$ & 0.13 (NS) & 0.30 (NS) & 0.64 (NS) \\
\hline Epilepsy & $1(0.3 \%)$ & $8(1.7 \%)$ & $0(0 \%)$ & 0.08 (NS) & 0.46 (NS) & 0.01 \\
\hline Smoking during 1st trimester of pregnancy & $22(7.3 \%)$ & $39(8.5 \%)$ & $25(7.1 \%)$ & 0.91 (NS) & 0.33 (NS) & 0.32 (NS) \\
\hline $\begin{array}{l}\text { Exposure to ionizing radiation during 1st trimester } \\
\text { of pregnancy }\end{array}$ & $1(0.3 \%)$ & $2(0.4 \%)$ & $1(0.3 \%)$ & 0.99 (NS) & 0.80 (NS) & 0.75 (NS) \\
\hline
\end{tabular}

${ }^{\$}$ Marginal totals for some variables may be different because of missing values.

NS: Not significant.

study, there were no PPD1 cases born to mothers with diabetes type I or II, thus it is unlikely to be an important risk factor. However, among mothers of children with sporadic PPD1 we observed a trend for increased frequency of epilepsy and upper respiratory infections during the $1^{\text {st }}$ trimester of pregnancy. Finally, we confirmed that oligohydramnios occurred more frequently in both sporadic and familial forms of polydactyly compared to healthy control births. Although oligohydramnios classically results from congenital abnormalities of the kidney or urinary tract, and can lead to well-defined deformation sequences $[17,18]$, it has been described in association with other congenital malformations, such as digestive tract and cardiac malformations [19]. The etiologial basis for the observed association of oligohydramios with polydactylies remains unexplained.

A large body of scientific literature implicates genetic factors in the etiology of preaxial polydactyly [1,6-9]. Compared to other types of polydactyly, PPD1 has a relatively low familial recurrence [20,21]. In our study, $11 \%$ of all PPD1 cases were familial. However, family aggregation studies report that different types of preaxial polydactyly frequently occur within the same family. For example, extra hand digit, triphalangeal thumb, or duplication of the big toe may segregate within the same family, thus might represent manifestations of the same autosomal dominant mutation. This pleiotropic effect of causal mutations may be explained by the presence of additional environmental modifiers that may alter phenotypic expression of such genetic defects $[22,23]$. Importantly, our study suggests several environmental factors that may contribute to the expression of digital defects, including low birthweight, lower paternal education status, and selected pregnancy complications, such as oligohydramios.

\section{Conclusions}

In summary, our study provides additional support for the hypothesis that non-genetic factors play an important role in the etiology of sporadic PPD1. Low birthweight is one of the most strongly associated risk factors for sporadic PPD1 in our study. This observation, however, will require validation in independent case-control cohorts.

\section{Competing interests}

The authors declare no competing interests.

\section{Authors' contributions}

AM-K: Study conception, design, and implementation. AJ, KW: Literature review and manuscript preparation. BW: Statistical analysis. JL: Data collection from Pomorskie administrative region. MB-K: Data collection from Mazowieckie administrative region. HS-O: Data collection from Lubelskie administrative region. ES-W: Data collection from Warmińsko-mazurskie administrative region. AL-B: Supervision of the field activities. All authors read and approved the final manuscript. 


\section{Author details}

${ }^{1}$ Chair and Department of Medical Genetics, Poznan University of Medical Sciences, Poznan, Poland. ${ }^{2}$ Department of Preventive Medicine, Poznan University of Medical Sciences, Poznan, Poland. ${ }^{3}$ Department of Computer Science and Statistics, Poznan University of Medical Sciences, Poznan, Poland. ${ }^{4}$ Chair and Department of Biology and Genetics, Medical University of Gdansk, Gdansk, Poland. ${ }^{5}$ Department of Neonatology and Neonatal Intensive Care, Medical University of Warsaw, Warsaw, Poland. ${ }^{6}$ Department of Obstetrics and Pathology of Pregnancy, Medical University of Lublin, Lublin, Poland. ${ }^{7}$ Regional Children's Specialized Hospital, Olsztyn, Poland.

Received: 31 August 2012 Accepted: 11 February 2013

Published: 19 February 2013

\section{References}

1. Lettice LA, Heaney SJ, Purdie LA, Li L, de Beer P, Oostra BA, Goode D, Elgar $G$, Hill RE, de Graaff E: A long-range Shh enhancer regulates expression in the developing limb and fin and is associated with preaxial polydactyly. Hum Mol Genet 2003, 12(14):1725-1735.

2. Martinez-Frias ML, Bermejo E, Cereijo A: Preaxial polydactyly of feet in infants of diabetic mothers: epidemiological test of a clinical hypothesis. Am J Med Genet 1992, 42(5):643-646.

3. Smithells RW, Newman CG: Recognition of thalidomide defects. J Med Genet 1992, 29(10):716-723.

4. Latos-Bielenska A, Materna-Kiryluk A: Polish Registry of Congenital Malformations - aims and organization of the registry monitoring 300 000 births a year. J Appl Genet 2005, 46(4):341-348.

5. Polish Central Statistical Office: Public Information Bulletin 2006 (in Polish). [http://www.stat.gov.pl/gus].

6. Ray AK: A pedigree with bilateral preaxial polydactyly from India. J Genet Hum 1987, 35(4):267-274.

7. Gurnett CA, Bowcock AM, Dietz FR, Morcuende JA, Murray JC, Dobbs MB: Two novel point mutations in the long-range SHH enhancer in three families with triphalangeal thumb and preaxial polydactyly. Am J Med Genet A 2007, 143(1):27-32

8. Radhakrishna U, Bornholdt D, Scott HS, Patel UC, Rossier C, Engel H, Bottani A, Chandal D, Blouin JL, Solanki JV, et al: The phenotypic spectrum of GLI3 morphopathies includes autosomal dominant preaxial polydactyly type-IV and postaxial polydactyly type-A/B; No phenotype prediction from the position of GLI3 mutations. Am J Hum Genet 1999, 65(3):645-655.

9. Fujioka H, Ariga T, Horiuchi K, Otsu M, Igawa H, Kawashima K, Yamamoto Y, Sugihara T, Sakiyama Y: Molecular analysis of non-syndromic preaxial polydactyly: preaxial polydactyly type-IV and preaxial polydactyly type-I. Clin Genet 2005, 67(5):429-433.

10. Gissler M, Merilainen J, Vuori E, Hemminki E: Register based monitoring shows decreasing socioeconomic differences in Finnish perinatal health. J Epidemiol Community Health 2003, 57(6):433-439.

11. Reime B, Ratner PA, Tomaselli-Reime SN, Kelly A, Schuecking BA, Wenzlaff P: The role of mediating factors in the association between social deprivation and low birth weight in Germany. Soc Sci Med 2006, 62(7):1731-1744

12. Orioli IM, Castilla EE: Thumb/hallux duplication and preaxial polydactyly type I. Am J Med Genet 1999, 82(3):219-224.

13. Merline AC, O'Malley PM, Schulenberg JE, Bachman JG, Johnston LD: Substance use among adults 35 years of age: prevalence, adulthood predictors, and impact of adolescent substance use. Am J Public Health 2004, 94(1):96-102.

14. Redonnet B, Chollet A, Fombonne E, Bowes L, Melchior M: Tobacco, alcohol, cannabis and other illegal drug use among young adults: The socioeconomic context. Drug Alcohol Depend 2012, 121(3):231-239.

15. Man LX, Chang B: Maternal cigarette smoking during pregnancy increases the risk of having a child with a congenital digital anomaly. Plast Reconstr Surg 2006, 117(1):301-308

16. Aberg A, Westbom $L$, Kallen B: Congenital malformations among infants whose mothers had gestational diabetes or preexisting diabetes. Early Hum Dev 2001, 61(2):85-95.

17. Christianson C, Huff D, McPherson E: Limb deformations in oligohydramnios sequence: effects of gestational age and duration of oligohydramnios. Am J Med Genet 1999, 86(5):430-433.
18. Martinez-Frias ML, Bermejo E, Rodriguez-Pinilla E, Frias JL: Maternal and fetal factors related to abnormal amniotic fluid. J Perinatol 1999 19(7):514-520.

19. Stoll C, Alembik Y, Roth MP, Dott B: Study of 224 cases of oligohydramnios and congenital malformations in a series of 225,669 consecutive births. Community Genet 1998, 1(2):71-77.

20. Castilla E, Paz J, Mutchinick O, Munoz E, Giorgiutti E, Gelman Z: Polydactyly: a genetic study in South America. Am J Hum Genet 1973, 25(4):405-412.

21. Miura T, Nakamura R, Horii E: Congenital hand anomalies in Japan: a family study. J Hand Surg Am 1990, 15(3):439-444.

22. Radhakrishna U, Multani AS, Solanki JV, Shah VC, Chinoy NJ: Polydactyly: a study of a five generation Indian family. J Med Genet 1993, 30(4):296-299.

23. Graham JM Jr, Brown FE, Hall BD: Thumb polydactyly as a part of the range of genetic expression for thenar hypoplasia. Clin Pediatr (Phila) 1987, 26(3):142-148.

doi:10.1186/1471-2431-13-26

Cite this article as: Materna-Kiryluk et al:: Epidemiology of isolated preaxial polydactyly type I: Data from the Polish Registry of Congenital Malformations (PRCM). BMC Pediatrics 2013 13:26.

\section{Submit your next manuscript to BioMed Central and take full advantage of:}

- Convenient online submission

- Thorough peer review

- No space constraints or color figure charges

- Immediate publication on acceptance

- Inclusion in PubMed, CAS, Scopus and Google Scholar

- Research which is freely available for redistribution
C Biomed Central 